\title{
Association between sleep apnoea and pulmonary hypertension in Kyrgyz highlanders
}

\author{
Tsogyal D. Latshang ${ }^{1}$, Michael Furian, Sayaka S. Aeschbacher ${ }^{1}$, Silvia Ulrich, \\ Batyr Osmonov ${ }^{2}$, Erkin M. Mirrakhimov ${ }^{2,3}$, Jainagul Isakova ${ }^{4}$, \\ Almaz A. Aldashev ${ }^{4}$, Talant M. Sooronbaev ${ }^{2}$ and Konrad E. Bloch ${ }^{1}$
}

Affiliations: ${ }^{1}$ Clinic of Pneumology and Sleep Disorders Center, University Hospital Zurich, Zurich, Switzerland. ${ }^{2}$ Dept of Respiratory, Critical Care and Sleep Medicine, National Center for Cardiology and Internal Medicine, Bishkek, Kyrgyz Republic. ${ }^{3}$ Kyrgyz State Medical Academy, Bishkek, Kyrgyz Republic. ${ }^{4}$ Research Institute for Molecular Biology and Medicine, Bishkek, Kyrgyz Republic.

Correspondence: Konrad E. Bloch, Pulmonary Division, University Hospital of Zurich, Raemistrasse 100, 8091 Zurich, Switzerland. E-mail: konrad.bloch@usz.ch

@ERSpublications

PH in highland residents is associated with sleep apnoea, suggesting a pathophysiologic interaction http://ow.ly/CQ1k305CQeq

Cite this article as: Latshang TD, Furian M, Aeschbacher SS, et al. Association between sleep apnoea and pulmonary hypertension in Kyrgyz highlanders. Eur Respir J 2017; 49: 1601530 [https://doi.org/10.1183/ 13993003.01530-2016].

ABSTRACT This case-control study evaluates a possible association between high altitude pulmonary hypertension (HAPH) and sleep apnoea in people living at high altitude.

Ninety highlanders living at altitudes $>2500 \mathrm{~m}$ without excessive erythrocytosis and with normal spirometry were studied at $3250 \mathrm{~m}$ (Aksay, Kyrgyzstan); 34 healthy lowlanders living below $800 \mathrm{~m}$ were studied at $760 \mathrm{~m}$ (Bishkek, Kyrgyzstan). Echocardiography, polysomnography and other outcomes were assessed. Thirty-six highlanders with elevated mean pulmonary artery pressure (mPAP) $>30 \mathrm{mmHg}$ (31-42 mmHg by echocardiography) were designated as HAPH+. Their data were compared to that of 54 healthy highlanders ( $\mathrm{HH}, \mathrm{mPAP} 13-28 \mathrm{mmHg}$ ) and 34 healthy lowlanders (LL, mPAP 8-24 mmHg).

The HAPH+ group (median age 52 years (interquartile range 47-59) had a higher apnoea-hypopnoea index (AHI) of 33.8 events. $\mathrm{h}^{-1}(26.9-54.6)$ and spent a greater percentage of the night-time with an oxygen saturation $<90 \%(\mathrm{~T}<90 ; 78 \%(61-89))$ than the HH group (median age 39 years $(32-48)$, AHI 9.0 events $\cdot \mathrm{h}^{-1}$ (3.6-16), T<90 33\% (10-69)) and the LL group (median age 40 years (30-47), AHI 4.3 events.h ${ }^{-1}(1.4-12.6)$, $\mathrm{T}<900 \%(0-0)) ; \mathrm{p}<0.007$ for $\mathrm{AHI}$ and $\mathrm{T}<90$, respectively, in $\mathrm{HAPH}+$ versus others. In highlanders, multivariable regression analysis confirmed an independent association between mPAP and both AHI and $\mathrm{T}<90$, when controlled for age, gender and body mass index.

Pulmonary hypertension in highlanders is associated with sleep apnoea and hypoxaemia even when adjusted for age, gender and body mass index, suggesting pathophysiologic interactions between pulmonary haemodynamics and sleep apnoea.

This article has supplementary material available from erj.ersjournals.com

Received: July 312016 | Accepted after revision: Oct 212016

Support statement: This study was supported by grants from the OPO Foundation and the Lung League Zurich, Switzerland. Philips Respironics Switzerland contributed some of the measurement equipment used in this study. Siemens Healthcare Diagnostics AG (Zurich, Switzerland) provided the blood gas analyser and NDD Medizintechnik AG (Zurich, Switzerland) provided spirometers for lung function studies. Funding information for this article has been deposited with the Open Funder Registry.

Conflict of interest: None declared.

Copyright OERS 2017 


\section{Introduction}

More than 120 million persons worldwide are estimated to live in mountain areas at altitudes above $2500 \mathrm{~m}$ [1]. Assuming a prevalence of chronic altitude-related illnesses such as high altitude pulmonary hypertension (HAPH) or chronic mountain sickness (CMS) of 5-10\% among highlanders, several million people are estimated to be affected. HAPH affects permanent residents at altitudes greater than $2500 \mathrm{~m}[1,2]$. It may lead to dyspnoea, impaired exercise performance and, in advanced stages, right heart failure and premature death. A descent to a lower altitude and administration of oxygen and drugs that lower pulmonary arterial pressure have been proposed as treatments for HAPH [2-4]. According to international consensus [1], diagnostic criteria for $\mathrm{HAPH}$ include a mean pulmonary arterial pressure (mPAP) $>30 \mathrm{mmHg}$ or a systolic pulmonary arterial pressure (sPAP) $>50 \mathrm{mmHg}$ measured in highlanders at their altitude of residence, right ventricular hypertrophy, signs of heart failure, moderate hypoxaemia in the absence of coexistent cardiopulmonary disease and excessive erythrocytosis (haemoglobin concentration $<19 \mathrm{~g} \cdot \mathrm{dL}^{-1}$ in females and $<21 \mathrm{~g} \cdot \mathrm{dL}^{-1}$ in males). The prevalence of HAPH is not exactly known. However, among 741 permanent high altitude residents in the Kyrgyz Republic, $14 \%$ had one or more ECG signs of cor pulmonale; additionally, in $20 \%$ of 136 Kyrgyz highlanders with exertional dyspnoea at altitude, right heart catheterisation at low altitude $(700 \mathrm{~m})$ revealed an mPAP $>25 \mathrm{mmHg}$, consistent with pulmonary hypertension [2]. The pathophysiology of HAPH is still incompletely understood. A genetic susceptibility [2, 5-8], polycythaemia, heart and lung diseases, and disturbances in control of breathing have been discussed as predisposing factors for HAPH. However, their role in the pathophysiology of HAPH has not been confirmed by robust evidence. In particular, whether sleep apnoea and sleep-related hypoventilation are associated with or may even promote HAPH has not been studied. Therefore, the purpose of the current study was to investigate the prevalence of sleep-related breathing disturbances and clinical characteristics of highlanders with and without HAPH in comparison to those in healthy lowlanders. We tested the hypotheses that highlanders with HAPH have a greater amount of sleep apnoea and a lower nocturnal oxygen saturation than healthy highlanders and lowlanders, and that the amount of sleep apnoea correlates with pulmonary artery pressure in highlanders.

\section{Methods}

\section{Study design and setting}

This prospective case-control study was performed from June to October 2012 in the Kyrgyz Republic. Highlanders, mostly nomads, living in yurts at altitudes of $2800-3800 \mathrm{~m}$ in the Aksay high altitude plateau area were invited during visits of the highland areas to participate in studies performed at the Aksay health post located at $3250 \mathrm{~m}$ (mean barometric pressure $519 \mathrm{mmHg}$ ). Participants travelled by horse or walked for up to 1 day from their residence to the health post and stayed there for 1 night for examinations. Healthy Kyrgyz lowlanders living in the capital of Bishkek were invited to undergo the same examinations as the highlanders in the National Center of Cardiology and Internal Medicine, Bishkek (altitude $760 \mathrm{~m}$, mean barometric pressure $697 \mathrm{mmHg}$ ).

Methods are further detailed in the supplementary material.

\section{Participants}

Male and female highlanders of Kyrgyz ethnicity who were born, raised and currently living at $>2500 \mathrm{~m}$ and $>16$ years old were invited to participate in the studies at the Aksay health post at $3250 \mathrm{~m}$. Participants were allocated into either the group with HAPH (designated HAPH+, some of them known to the study team from previous visits) or into the group without HAPH (i.e. healthy highlanders, designated $\mathrm{HH}$ ) based on whether echocardiographic evaluation revealed an mPAP $>30$ or $\leqslant 30 \mathrm{mmHg}$, respectively [1]. Exclusion criteria were excessive erythrocytosis (haemoglobin concentration in females $>19 \mathrm{~g} \cdot \mathrm{dL}^{-1}$, in males $>21 \mathrm{~g} \cdot \mathrm{dL}^{-1}$ ), forms of pulmonary hypertension other than $\mathrm{HAPH}$, as well as the presence of other cardio-respiratory or sleep disorders, smoking $>10$ cigarettes per day or a history of smoking $>20$ pack-years, or regular intake of medication that may interfere with the control of breathing. Informed written consent was obtained and the ethics committee of the National Center of Cardiology and Internal Medicine, Bishkek, approved the study (www.ClinicalTrials.gov NCT01621061).

\section{Assessments}

A medical history and physical examination including body height, weight and assessment of leg oedema (graded as absent or present) were obtained. Symptoms and quality of life were assessed by the New York Heart Association (NYHA) functional classification, the Qinghai CMS score [1], the SF-36 quality of life questionnaire [9], the Kansas City Cardiomyopathy Questionnaire [10] and the Epworth Sleepiness Scale [11].

Full polysomnography including neurophysiological signals, pulse oximetry, nasal pressure swings, respiratory inductance plethysmography, diaphragmatic surface electromyogram (EMG) and transcutaneous $\mathrm{PCO}_{2}$ monitoring was performed as described previously [12]. Apnoeas and hypopnoeas were defined as a reduction of the nasal pressure swings or the inductive plethysmographic sum signal to $<50 \%$ of the baseline 
during $>10$ s of monitoring. Obstructive and central events were differentiated by the presence or absence of asynchronous rib cage-abdominal movement, diaphragmatic surface EMG activity and signs of flow limitation in the nasal pressure signal contour (supplementary material and $[12,13])$. The morning after the sleep study, subjective sleep quality was assessed on a visual analogue scale ranging from 0 (extremely poor) to $100 \mathrm{~mm}$ (excellent), and patients were asked to estimate the time spent awake during the previous night [12]. Vigilance was evaluated by the psychomotor vigilance test [14] and cognitive performance by the trail-making test [15].

Doppler-echocardiography (SpectraMax; SonoSite, Bothell,WA, USA) was performed to estimate mPAP from pulmonary artery flow acceleration time according to Kitabatake $(\log 10(\mathrm{mPAP})=(-0.0068 \times$ acceleration time $+2.1 \mathrm{mmHg})$ ) [16] and as previoulsy validated by right heart catheterisation in 60 Kyrgyz highlanders with and without HAPH (bias of mPAP by echocardiography versus right heart catheterisation $0.5 \mathrm{mmHg}$, 95\% CI -9.5 to $10.5 \mathrm{mmHg}$ ) [17]. The sPAP was estimated as the sum of the trans-tricuspid pressure gradient determined by continuous-wave Doppler and the central venous pressure estimated from the inspiratory inferior vena cava collapse. Right and left heart dimensions were also acquired. The investigators performing echocardiographies were blinded to the results of the sleep studies. Further details are presented in the supplementary material.

Spirometry and a 6-minute walk test were performed according to standard guidelines. Systemic blood pressure measurements were obtained in the morning, during the day and in the evening, each time in triplicate, using a validated device (BPA80; Microlife, Widnau, Switzerland) and the median of these nine measurements is reported. It was not feasible to carry out $24 \mathrm{~h}$ blood pressure monitoring. Arterial blood gases and haemoglobin concentration were measured in a radial artery blood sample (RapidPoint 405; Siemens Healthcare Diagnostics AG, Zurich, Switzerland) drawn in the morning after sleep studies. Analyses of gene polymorphisms associated with pulmonary hypertension and vascular dysfunction were performed in venous blood samples.

\section{Primary outcomes and sample size estimation}

Primary outcomes were the apnoea-hypopnoea index (AHI) and the nocturnal oxygen saturation measured by pulse oximetry $\left(\mathrm{SpO}_{2}\right)$. Minimal important differences and standard deviation were assumed as $15 \pm 20$ events. $\mathrm{h}^{-1}$ in $\mathrm{AHI}$ and as $3 \pm 4 \%$ in mean nocturnal $\mathrm{SpO}_{2}$. To achieve a power of 0.8 (alpha 0.05 ) to detect these differences, we aimed to recruit $>32$ participants per group including a $10 \%$ drop-out rate.

\section{Statistics}

Data are summarised as medians (quartiles) to account for non-normal data distribution. Between-group comparisons were performed by Mann-Whitney $U$ tests. Effects of sleep apnoea and nocturnal hypoxaemia on mPAP in highlanders $(\mathrm{HAPH}+$ and $\mathrm{HH})$ were evaluated by multiple logistic regression analysis controlling for several potential confounders; i.e. quintiles of mPAP were the dependent variable with the AHI, percentage of night-time spent with $\mathrm{SpO}_{2}<90 \%$, forced expiratory volume in $1 \mathrm{~s}$ (FEV1), body mass index, genotypes, age and gender as independent variables. Independent variables with $\mathrm{p}<0.2 \mathrm{in}$ univariate analysis, age and gender were maintained in multivariable analyses. To account for an imbalance in gender and age in the $\mathrm{HAPH}+$ and $\mathrm{HH}$ groups, additional comparisons were performed in two subgroups of $21 \mathrm{HAPH}+$ and $21 \mathrm{HH}$ individuals matched for gender, age (within 10 years) and body mass index (within $5 \mathrm{~kg} \cdot \mathrm{m}^{-2}$ ). Significance was assumed at $\mathrm{p}<0.05$.

\section{Results}

Of 232 screened highlanders, 90 met the inclusion criteria and participated in the study; 36 had an elevated mPAP $>30 \mathrm{mmHg}$ and were therefore allocated to the HAPH+ group; 54 healthy highlanders had an mPAP $<30 \mathrm{mmHg}$ and formed the HH group. Of 39 screened lowlanders, 35 met the inclusion criteria and participated; one data set was missing because of a technical failure. The data from a total of 124 participants were available for analysis (figure 1).

Participants were predominantly middle-aged men (table 1) but the HAPH+ group was older (median 52 years) than the $\mathrm{HH}$ (39 years) and LL (40 years) groups. The highlanders were shorter than the lowlanders. The weight of the $\mathrm{HAPH}+$ group was higher than that of the $\mathrm{HH}$ group, resulting in a higher body mass index. The HAPH+ group had a higher systemic arterial blood pressure and heart rate than the $\mathrm{HH}$ group. Five of $36 \mathrm{HAPH}+$ participants, 2 of $54 \mathrm{HH}$ participants and none of LL participants had leg oedema (Chi-squared $\mathrm{HAPH}+$ versus $\mathrm{HH}, \mathrm{p}=0.08$ ). The median NYHA functional class was 1 in the $\mathrm{HAPH}+$ group and 0 in the HH and LL groups. The Epworth scores did not suggest excessive sleepiness in any of the three study groups. Although the CMS scores were statistically significantly higher in the $\mathrm{HAPH}+$ group compared to the other groups, the values were low (table 1). 

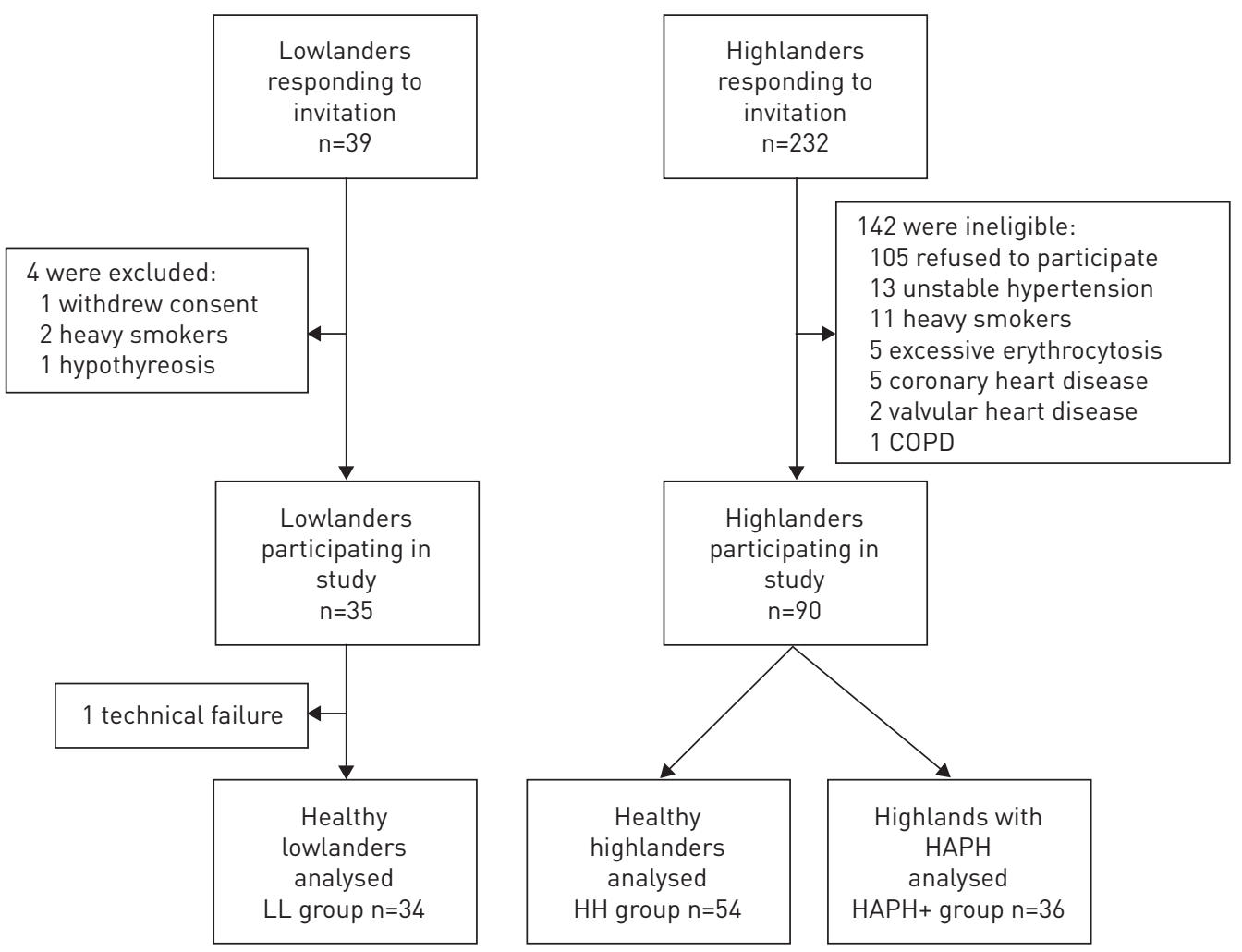

FIGURE 1 Patient flow. Of 232 screened highlanders, 90 fulfilled selection criteria, 36 had an elevated mean pulmonary artery pressure (mPAP) $>30 \mathrm{mmHg}$ and were designated as highlanders with high altitude pulmonary hypertension (HAPH+ group), and 54 had an $\mathrm{mPAP}<30 \mathrm{mmHg}$ and were designated as healthy highlanders (HH group). Of 39 lowlanders, 35 fulfilled selection criteria and were included: one data set was not available because of a technical failure, so data from 34 participants designated as healthy lowlanders (LL group) were analysed.

The SF-36 and the Kansas City Cardiomyopathy Questionnaires revealed reduced quality of life scores in the HAPH+ compared to the HH and LL groups.

According to group allocation, mPAP was higher (by $10 \mathrm{mmHg}$ ) in the $\mathrm{HAPH}+$ than in the $\mathrm{HH}$ group; and mPAP in the HH group was higher than in the LL group. Correspondingly, in participants with trans-tricuspid regurgitation, the sPAP was also highest in the $\mathrm{HAPH}+$ group, intermediate in the $\mathrm{HH}$ group and lowest in the LL group (table 1). The right ventricular diastolic diameter and wall thickness were greater in the $\mathrm{HAPH}+$ than in the $\mathrm{HH}$ and LL groups. The left ventricular posterior wall thickness was similar in the three groups but the left ventricular ejection fraction was slightly lower in the HAPH+ than in the $\mathrm{HH}$ and LL groups.

The 6-minute walk distance was lowest in the HAPH+ group, intermediate in the HH group and highest in the LL group. Spirometry was normal in all three groups. Both highlander groups had a lower arterial carbon dioxide tension $\left(\mathrm{PaCO}_{2}\right)$, arterial oxygen tension $\left(\mathrm{PaO}_{2}\right)$ and arterial oxygen saturation $\left(\mathrm{SaO}_{2}\right)$ than the lowlanders. In the HAPH+ group, the arterial $\mathrm{pH}$ was higher and $\mathrm{PaO}_{2}$ and $\mathrm{SaO}_{2}$ were lower than in the $\mathrm{HH}$ group but the $\mathrm{PaCO}_{2}$ was similar in the two highlander groups. The alveolar-arterial $\mathrm{PO}_{2}$ difference was therefore greater in the $\mathrm{HAPH}+$ than in the $\mathrm{HH}$ group. The haematocrit and the haemoglobin concentration were higher in highlanders than in lowlanders but not in the range of erythrocytosis (according to selection criteria) and similar between the $\mathrm{HAPH}+$ and $\mathrm{HH}$ groups. The frequencies of evaluated gene polymorphisms were not statistically different between the HAPH+ and HH groups (supplementary material, table E1).

\section{Sleep and vigilance studies}

The HAPH+ group had pronounced nocturnal hypoxaemia and a significantly higher AHI with repetitive oxygen desaturations, mainly due to obstructive and, to a lesser extent, central apnoeas, compared with the $\mathrm{HH}$ and LL groups (table 2, figure 2).

The $\mathrm{HH}$ group had a lower nocturnal $\mathrm{SpO}_{2}$ and a slightly higher central AHI compared to the LL group. The transcutaneous $\mathrm{PCO}_{2}$ was similar among the three groups. The HAPH+ group had reduced sleep efficiency and a greater amount of wakefulness after sleep onset than the HH and LL groups. The relative 
TABLE 1 Main participant characteristics

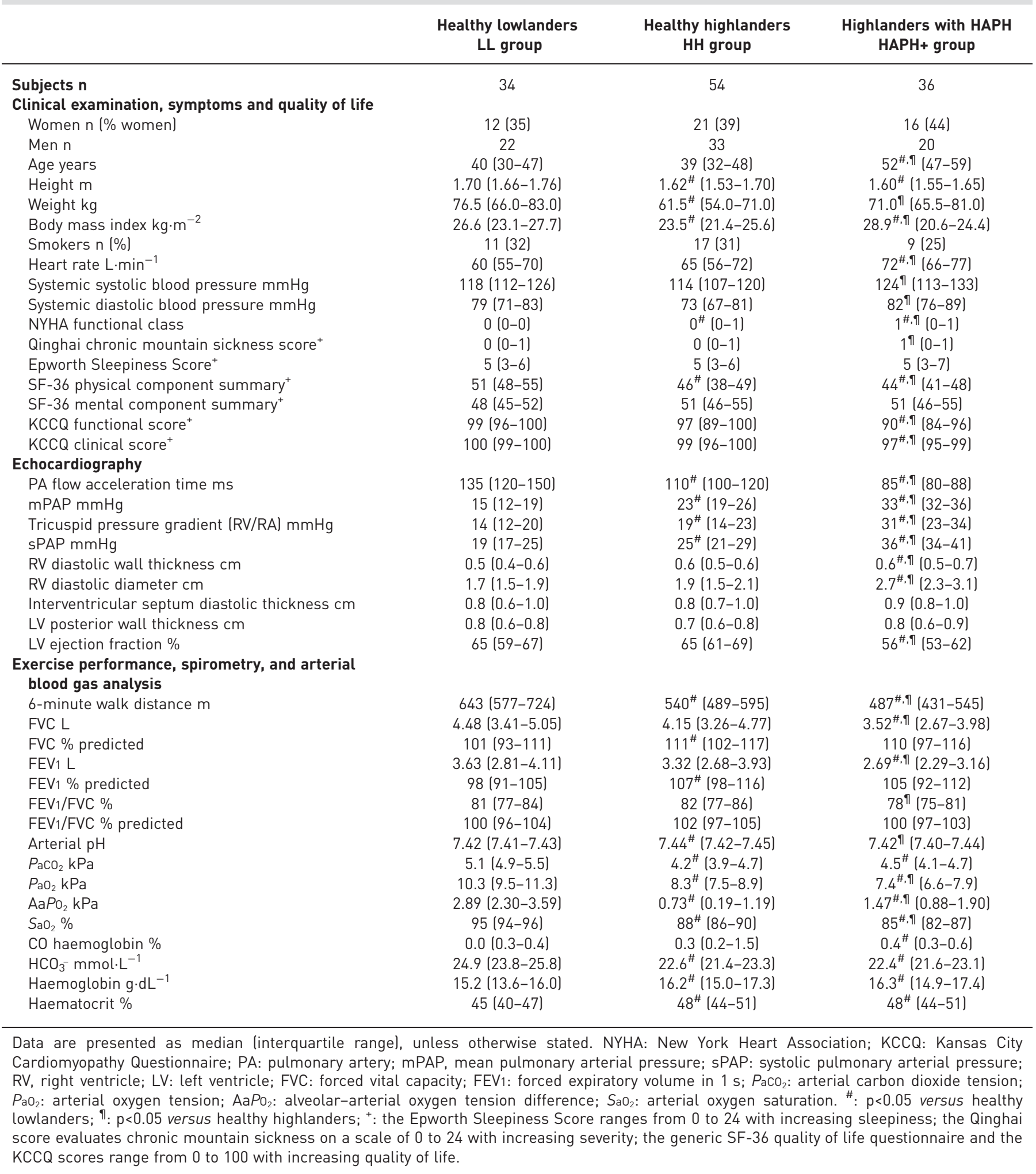

amount of deep sleep, non-rapid eye movement (NREM) stages 3 and 4, was similar in the three groups but the highlanders had a slightly lower amount of rapid eye movement (REM) sleep than the lowlanders. The arousal index was similarly low in all three groups. The heart rate and the incidence of ventricular extra beats were increased in the HAPH+ compared to the HH and LL groups (table 2). 


\begin{tabular}{|c|c|c|c|}
\hline & $\begin{array}{l}\text { Healthy lowlanders } \\
\text { LL group }\end{array}$ & $\begin{array}{c}\text { Healthy highlanders } \\
\text { HH group }\end{array}$ & $\begin{array}{l}\text { Highlanders with HAPH } \\
\text { HAPH+ group }\end{array}$ \\
\hline Subjects $\mathrm{n}$ & 34 & 54 & 36 \\
\hline Obstructive AHI events $\cdot \mathrm{h}^{-1}$ & $3.7(0.4-11.8)$ & $5.1(1.8-13.3)$ & $24.6^{\#, \text {. }}(15.4-52.8)$ \\
\hline Central AHI events $\cdot \mathrm{h}^{-1}$ & $0.6(0.1-1.2)$ & $1.4^{\#}(0.8-3.6)$ & $5.2^{\#, \text {. }}(2.3-9.3)$ \\
\hline Mean nocturnal $\mathrm{SpO}_{2} \%$ & 96 (95-97) & $90^{\#}(88-92)$ & $87^{\#, 91}(84-88)$ \\
\hline $\mathrm{PtcCO}_{2}$ in NREM sleep $\mathrm{kPa}$ & $5.7(5.2-6.1)$ & $5.5(4.9-5.7)$ & $5.6(4.8-6.1)$ \\
\hline $\mathrm{PtcCO}_{2}$ in REM sleep $\mathrm{kPa}$ & $5.7(5.3-6.3)$ & $5.5(5.1-5.9)$ & $5.7(5.0-6.3)$ \\
\hline Total sleep time min & 449 (399-498) & $432(404-481)$ & $407^{\#}(357-444)$ \\
\hline Sleep efficiency \% TIB & $86(76-89)$ & $83(75-89)$ & $78^{\#, 91}(67-82)$ \\
\hline WASO $\mathrm{min}$ & $44(20-90)$ & $72^{\#}(42-111)$ & $104^{\#, 91}(78-130)$ \\
\hline Sleep latency min & $17(12-32)$ & $17(11-43)$ & $16(10-35)$ \\
\hline Heart rate $\mathrm{min}^{-1}$ & $61(55-69)$ & $65(59-72)$ & $75^{\#, 9}(69-79)$ \\
\hline Premature ventricular beats during TIB events $\cdot \mathrm{h}^{-1}$ & $0.0(0.0-0.0)$ & $0.0(0.0-0.0)$ & $0.0^{\#, 9}(0.0-1.03)$ \\
\hline PVT reaction time $\mathrm{ms}$ & $237(217-323)$ & $347^{\#}(277-418)$ & $384^{\#, 91}(329-596)$ \\
\hline Trail making test $\mathbf{s}$ & $85(73-111)$ & $121^{\#}(103-146)$ & $156^{\#, \uparrow(134-177)}$ \\
\hline Estimated night-time spent awake min & $10(5-20)$ & $20^{\#}(10-60)$ & $30^{\#}(10-53)$ \\
\hline Subjective sleep quality visual analogue score ${ }^{+}$ & $50(43-78)$ & $61(46-76)$ & $50(41-66)$ \\
\hline \multicolumn{4}{|c|}{$\begin{array}{l}\text { Data are presented as median (interquartile range), unless otherwise stated. } \mathrm{AHI} \text { : apnoea-hypopnoea index; } \mathrm{SpO}_{2} \text { : arterial oxygen saturation } \\
\text { measured by pulse oximetry; TIB: time in bed; ODI: oxygen desaturation index; } \mathrm{PtcO}_{2} \text { : transcutaneous carbon dioxide tension; WASO } \\
\text { wakefulness after sleep onset; NREM: non-rapid eye movement; TST: total sleep time; REM: rapid eye movement; PVT: psychomotor vigilance } \\
\text { test. }{ }^{\#}: p<0.05 \text { versus healthy lowlanders; }{ }^{\uparrow}: \mathrm{p}<0.05 \text { versus healthy highlanders; }{ }^{+} \text {: the range of the sleep quality visual analogue score was from } \\
0 \text { (extremely poor) to } 100 \text { (excellent). }\end{array}$} \\
\hline
\end{tabular}

The morning after sleep studies, the HAPH+, HH and LL groups indicated similar sleep quality scores on the visual analogue scale but highlanders estimated that they had spent more time awake during the night than lowlanders. Performance in the psychomotor vigilance test and in the trail-making test was worst in the $\mathrm{HAPH}+$ group, intermediate in the $\mathrm{HH}$ group and best in the LL group (table 2).

Multiple regression analysis performed on data in highlanders ( $\mathrm{HAPH}+$ and $\mathrm{HH}$ ) revealed a significant and independent effect of both sleep apnoea and nocturnal oxygenation on the mPAP even when controlling for the effects of age, gender, body mass index and gene polymorphisms (table 3). Moreover, including daytime $\mathrm{SpO}_{2}$ as a predictor in the model confirmed that nocturnal oxygenation and sleep apnoea but not daytime oxygenation were significant independent predictors of mPAP in highlanders (supplementary table E2).
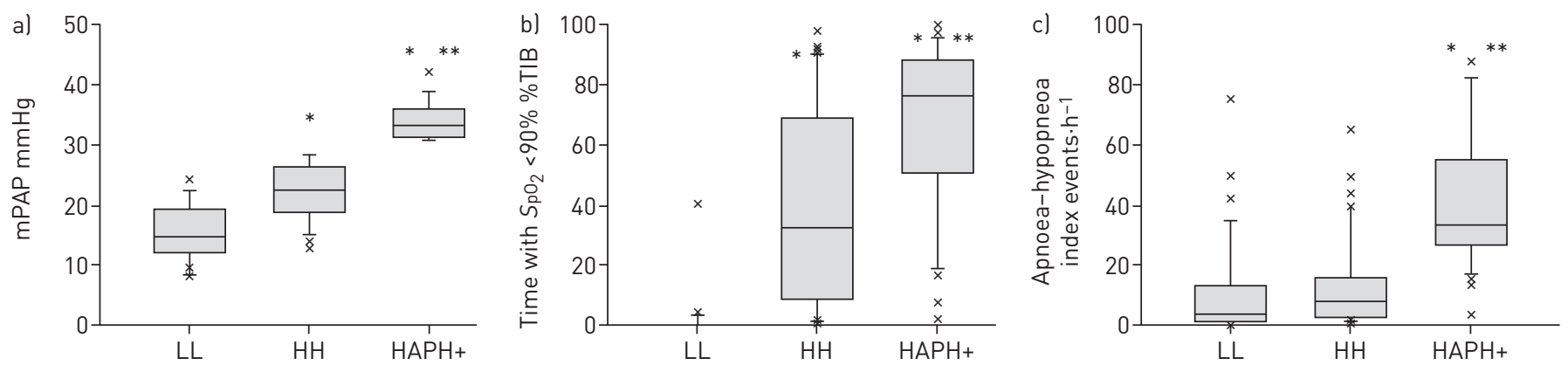

FIGURE 2 a) Mean pulmonary artery pressure (mPAP), b) time of the night spent with an oxygen saturation $\left(\mathrm{SpO}_{2}\right)<90 \%$ and c) apnoea-hypopnoea index are displayed for the groups of highlanders with high altitude pulmonary hypertension (HAPH+ group), healthy highlanders (HH) and healthy lowlanders (LL). Horizontal lines, boxes and whiskers represent the median, quartiles and the 10th and 90th percentiles, respectively; individual values beyond this range are displayed by a cross with the exception of one apnoea/hypopnoea data point with a value of 139 events. ${ }^{-1}$, which is out of the axis range. ${ }^{*} \mathrm{p}<0.05$ versus $\mathrm{LL},{ }^{* *} \mathrm{p}<0.05$ versus $\mathrm{HH}$. 
TABLE 3 Logistic regression analysis of mean pulmonary artery pressure in highlanders

\begin{tabular}{|c|c|c|c|c|c|c|}
\hline \multirow[t]{2}{*}{ Dependent variable } & \multicolumn{3}{|c|}{ Univariate analysis } & \multicolumn{3}{|c|}{ Multivariable model } \\
\hline & OR & $95 \% \mathrm{Cl}$ & p-value & OR & $95 \% \mathrm{Cl}$ & p-value \\
\hline Total AHI events $\cdot \mathrm{h}^{-1}$ & 1.064 & $1.040-1.089$ & $<0.001$ & 1.035 & $1.009-1.062$ & 0.008 \\
\hline Time in bed with $\mathrm{SpO}_{2}<90 \%$ & 1.032 & $1.019-1.045$ & $<0.001$ & 1.016 & $1.001-1.032$ & 0.043 \\
\hline Age years & 1.119 & $1.076-1.164$ & $<0.001$ & 1.081 & $1.032-1.132$ & 0.001 \\
\hline Sex & 0.955 & $0.450-2.026$ & 0.905 & 0.821 & $0.335-2.012$ & 0.667 \\
\hline FEV 1 \%predicted & 0.983 & $0.956-1.012$ & 0.259 & & & \\
\hline Body mass index $\mathrm{kg} \cdot \mathrm{m}^{-2}$ & 1.243 & $1.136-1.360$ & $<0.001$ & 1.041 & $0.933-1.161$ & 0.473 \\
\hline ACE $\mathrm{I} / \mathrm{I}^{+} \mathrm{n}$ & 0.998 & $0.549-1.812$ & 0.994 & & & \\
\hline eNOS $4 a / 4 a^{+} n$ & 1.395 & $0.574-3.391$ & 0.463 & & & \\
\hline eNOS G-894T ${ }^{+} n$ & 1.990 & $0.776-5.082$ & 0.152 & 1.001 & $0.308-3.252$ & 0.999 \\
\hline eNOS T-786C ${ }^{+} n$ & 1.929 & $0.874-4.258$ & 0.104 & 2.646 & $1.022-6.850$ & 0.045 \\
\hline 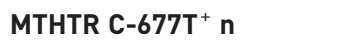 & 1.507 & $0.771-2.949$ & 0.231 & & & \\
\hline
\end{tabular}

90 observations at $3250 \mathrm{~m}$ ( $\mathrm{n}=83$ for genetic analyses). Independent variables with $\mathrm{p}$-value $<0.2$ in the univariate analysis and gender were included into the multivariable analysis. The multivariable model was adjusted for all variables listed, $\mathrm{R}^{2}$ was $0.244, \mathrm{p}<0.001$. AHI: apnoea-hypopnoea index; $\mathrm{SpO}_{2}$ : oxygen saturation; FEV1: forced expiratory volume in $1 \mathrm{~s}$; ACE: angiotensin-converting enzyme gene polymorphism; eNOS: endothelial nitric oxide synthase gene polymorphism; MTHTR: methylenetetrahydrofolate reductase gene polymorphism. " : quintiles of mean pulmonary artery pressure; ": female $=1$; male $=2 .^{+}$: genotypes were coded as $1=$ absence of indicated polymorphism, $2=$ indicated polymorphism in one allele, $3=$ indicated polymorphism in two alleles.

According to the regression model, each additional apnoea/hypopnoea event per hour increased the risk of a rise in mPAP by one quintile by $4 \%$, and each additional percentage time of the night spent with $\mathrm{S}_{\mathrm{PO}_{2}}$ $<90 \%$ increased the risk of a rise in mPAP by one quintile by $2 \%$.

A comparison of $21 \mathrm{HAPH}+$ and $21 \mathrm{HH}$ participants matched for age, gender and body mass index confirmed that $\mathrm{HAPH}+$ individuals had a higher AHI (median 28.0 versus 9.5 events. $\mathrm{h}^{-1}$ ) and spent a much longer time with $\mathrm{SpO}_{2}<90 \%$ (73\% versus $25 \%$ of time in bed) (supplementary material, table E3). The HAPH+ group had a higher mean nocturnal heart rate (76 versus 66 beats $\left.\mathrm{min}^{-1}\right)$ than the $\mathrm{HH}$ group $(\mathrm{p}<0.05$, all comparisons).

\section{Discussion}

The main findings of the current case-control study in Kyrgyz highlanders with HAPH were a mild to moderate elevation of the mPAP that was associated with a significantly higher AHI, mainly due to obstructive events, and a more pronounced hypoxaemia during sleep and wakefulness compared to individuals in the $\mathrm{HH}$ and LL groups. In the $\mathrm{HH}$ group, the mPAP was also higher and $\mathrm{SpO}_{2}$ was lower than the corresponding values in the LL group but the AHI was not significantly different from that in the LL group. In multiple regression analysis, the association between pulmonary artery pressure and sleep apnoea in highlanders remained significant even when potential confounders were accounted for, including the degree of hypoxaemia, age, gender, body mass index and polymorphisms in selected genes coding for angiotensin-converting enzyme and endothelial nitric oxide synthase. These findings are consistent with our hypothesis of an interaction between pulmonary hypertension and sleep apnoea in highlanders. Whether sleep apnoea may promote $\mathrm{HAPH}$, or vice versa, or whether the interaction is bidirectional requires further study. Our observations help to better understand the clinical and physiologic characteristics of highlanders with and without HAPH and to identify therapeutic targets for the treatment of HAPH.

In a recent systematic literature review [18] we identified few studies on sleep and breathing in life-long highland residents and, to our knowledge, no such studies have been performed in highlanders with HAPH. In patients with CMS, which is associated with severe hypoxaemia, erythrocytosis and pulmonary hypertension to a variable degree, both hypoventilation and sleep apnoea have been observed in some but not all studies [1, 19-21]. The association of CMS with sleep apnoea requires further study.

In the current study, the association of higher AHI with HAPH is consistent with but does not prove a contribution of sleep apnoea and intermittent hypoxaemia to elevations in pulmonary artery pressure in the Kyrgyz highlanders. Studies in patients with obstructive sleep apnoea living near sea level indicate that pulmonary hypertension is uncommon in the absence of coexisting pulmonary disease or hypoventilation [22]. The reduced $\mathrm{PaO}_{2}$ of highlanders with even mildly elevated mPAP (table 1, mPAP of $23 \mathrm{mmHg}$ in $\mathrm{HH}$ ) may render these individuals more susceptible to the development of HAPH in the presence of sleep apnoea and other conditions, such as advanced age or a genetic predisposition, that were significant independent 
predictors of mPAP in multiple regression analysis (table 3). Moreover, nocturnal but not daytime hypoxaemia predicted mPAP in the multiple regression analysis (supplementary material, table E2), providing further support for a role of sleep-related breathing disturbances in promoting pulmonary hypertension. Additional analyses in groups of $\mathrm{HAPH}+$ and $\mathrm{HH}$ matched for gender, age and body mass index corroborate the association of sleep apnoea and HAPH independent of these confounding factors (supplementary material, table E3). An impairment of pulmonary gas exchange with increasing mPAP, opening of a foramen ovale during sleep with right-left shunt [20] and pulmonary interstitial fluid accumulation [23] with associated excessive hypoxaemia might all have contributed to a vicious cycle with progressively worsening pulmonary haemodynamics in patients with HAPH [24]. Excessive pleural pressure swings due to obstructive apnoeas and interstitial pulmonary fluid accumulation, and an elevated sympathetic tone are considered to promote systemic hypertension and arrhythmia in lowlanders with obstructive sleep apnoea [25], and they might also contribute to HAPH in highlanders with sleep apnoea. The higher heart rate and systemic blood pressure and the greater number of extra beats in the HAPH+ compared to HH group (tables 1 and 2) support these assumptions. A rostral fluid shift in supine position has been suggested to increase upper airway resistance and promote obstructive sleep apnoea in patients with left heart failure [26] and this may also play a role in predisposing HAPH patients to obstructive apnoea. Whether the greater weight in the HAPH+ group was due to fluid retention or obesity remains elusive although the clinical examination revealed a trend for a higher prevalence of leg oedema in the HAPH+ versus $\mathrm{HH}$ group $(\mathrm{p}<0.08)$. Both HAPH+ and HH groups had a lower $\mathrm{PaCO}_{2}$ than the LL group (table 1), consistent with hypoxic stimulation of ventilation. Because the $\mathrm{PaCO}_{2}$ in the HAPH+ group was not lower than that in the $\mathrm{HH}$ group, despite a lower $\mathrm{PaO}_{2}$, a relative hypoventilation might play a role in promoting HAPH, as suggested in patients with CMS [27].

There is some evidence that pulmonary hypertension may promote sleep apnoea as we have observed a high prevalence of (predominantly central) sleep apnoea of $45 \%$ in lowlanders with precapillary pulmonary hypertension [28]. The mechanisms by which pulmonary hypertension may trigger apnoeas during sleep remain elusive but mechanisms similar to those in Cheyne-Stokes breathing in patients with left heart failure may play a role, such as a prolonged circulation time, for example [29]. Conditions associated with both sleep apnoea and pulmonary hypertension, including obesity, hypoventilation and older age, might also explain a common occurrence [22]. The higher body mass index of the HAPH+ compared to the HH group, although not quite in the obesity range, and the older age of the HAPH+ gourp would be consistent with this (table 1). Although the central AHI was higher in the HAPH+ compared to the HH group, the difference between the two groups in obstructive AHI was more important. Therefore, the mechanisms discussed above that predispose to central sleep apnoea in left heart failure may be less relevant in HAPH patients.

The sleep structure of the HAPH+ group was relatively well preserved. The main difference to the findings in the HH group were a greater duration of wakefulness after sleep onset, a reduced sleep efficiency and a higher percentage of superficial NREM sleep, whereas the number of arousals were similar in the HAPH+, $\mathrm{HH}$ and LL groups (table 2). Highlanders subjectively perceived a longer time of wakefulness during the night and the $\mathrm{HAPH}+$ group performed worse than the $\mathrm{HH}$ group in vigilance and cognitive tests during daytime. Whether this was due to hypoxaemia alone or additional factors, including sleep apnoea, intermittent hypoxia or differences in age, between the HAPH+ and $\mathrm{HH}$ groups remains elusive [30, 31].

We have based our main analysis on mPAP derived from pulmonary flow acceleration time because this echocardiographic index has closely agreed with mPAP measured using a right heart catheter in Kyrgyz highlanders [17], and because $\mathrm{mPAP}$ and acceleration time have been reported previously in several studies in highlanders $[2-4,32,33]$. Nevertheless, to allow comparisons to other studies reporting sPAP and/or the trans-tricupid pressure gradient (RV/RA) we also provide these indices (table 1). It is reassuring that the association of an elevated pulmonary artery pressure with sleep apnoea was a robust finding independent of the echocardiographic index used. The mean sPAP we measured in the HH and LL groups agrees closely with corresponding mean values computed from several individual studies in a recent meta-analysis [33]. Consistent with a long-standing elevation of pulmonary artery pressure, the right ventricular diameter and wall thickness were larger in the HAPH+ than in the HH and LL groups. The slightly reduced left ventricular ejection fraction in the HAPH+ group might have been due to effects of pronounced hypoxaemia on both ventricles and the older age. Although systemic blood pressure was higher in the HAPH+ than in the HH group, we had no evidence of left heart disease from history or clinical examination, and echocardiography did not reveal left ventricular hypertrophy. The blood pressure in the HH and LL groups was similar, consistent with studies in other non-Tibetan populations [34]. Studies in CMS patients have suggested dysfunction of both the systemic and pulmonary circulation [35] and this might also have applied to the HAPH+ group in the current study. Clinically, the impact of $\mathrm{HAPH}$ in the current study participants seemed to be modest because the median NYHA functional class of the HAPH+ group was only I. The CMS score was also low although still significantly different from that in the $\mathrm{HH}$ group. Because haemoglobin concentrations were not excessively elevated in the HAPH+ 
group and not different from those in the HH group, we had no evidence of early CMS in people with $\mathrm{HAPH}$ (table 1). Consistent with some effects of $\mathrm{HAPH}$, the quality of life scores were slightly lower in the $\mathrm{HAPH}+$ than in the $\mathrm{HH}$ group and the 6-minute walk distance was reduced.

In conclusion, the current comprehensive clinical and physiological study in Kyrgyz highlanders and lowlanders demonstrated an association between elevated pulmonary artery pressure and sleep apnoea in highlanders. Impairments in sleep structure, vigilance and cognitive performance, and the reduction in exercise performance of the $\mathrm{HAPH}+$ group compared to the $\mathrm{HH}$ group were mild but associated with a reduced quality of life. Therefore, randomised trials that corroborate these findings in other populations and ethnicities and that evaluate the efficacy of treatments for sleep apnoea and/or of HAPH in highlanders of different age groups would be desirable.

\section{References}

1 Leon-Velarde F, Maggiorini M, Reeves JT, et al. Consensus statement on chronic and subacute high altitude diseases. High Alt Med Biol 2005; 6: 147-157.

2 Aldashev AA, Sarybaev AS, Sydykov AS, et al. Characterization of high-altitude pulmonary hypertension in the Kyrgyz: association with angiotensin-converting enzyme genotype. Am J Respir Crit Care Med 2002; 166: 1396-1402.

3 Aldashev AA, Kojonazarov BK, Amatov TA, et al. Phosphodiesterase type 5 and high altitude pulmonary hypertension. Thorax 2005; 60: 683-687.

4 Kojonazarov B, Isakova J, Imanov B, et al. Bosentan reduces pulmonary artery pressure in high altitude residents. High Alt Med Biol 2012; 13: 217-223.

5 Leon-Velarde F, Mejia O. Gene expression in chronic high altitude diseases. High Alt Med Biol 2008; 9: 130-139.

6 Morrell NW, Sarybaev AS, Alikhan A, et al. ACE genotype and risk of high altitude pulmonary hypertension in Kyrghyz highlanders. Lancet 1999; 353: 814.

7 Wilkins MR, Ghofrani HA, Weissmann N, et al. Pathophysiology and treatment of high-altitude pulmonary vascular disease. Circulation 2015; 131: 582-590.

8 Zhao L, Oliver E, Maratou K, et al. The zinc transporter ZIP12 regulates the pulmonary vascular response to chronic hypoxia. Nature 2015; 524: 356-360.

9 Ware JE Jr, Snow KK, Kosinski M, et al. SF-36 health survey. Manual and interpretation guide. Boston, Medical Outcome Trust, New England Medical Centre, 1993.

10 Green CP, Porter CB, Bresnahan DR, et al. Development and evaluation of the Kansas City Cardiomyopathy Questionnaire: a new health status measure for heart failure. J Am Coll Cardiol 2000; 35: 1245-1255.

11 Bloch KE, Schoch OD, Zhang JN, et al. German version of the Epworth Sleepiness Scale. Respiration 1999; 66: 440-447.

12 Latshang TD, Nussbaumer-Ochsner Y, Henn RM, et al. Effect of acetazolamide and autoCPAP therapy on breathing disturbances among patients with obstructive sleep apnea syndrome who travel to altitude: a randomized controlled trial. JAMA 2012; 308: 2390-2398.

13 Nussbaumer-Ochsner Y, Schuepfer N, Ulrich S, et al. Exacerbation of sleep apnoea by frequent central events in patients with the obstructive sleep apnoea syndrome at altitude: a randomised trial. Thorax 2010; 65: 429-435.

14 Dinges DF, Pack F, Williams K, et al. Cumulative sleepiness, mood disturbance, and psychomotor vigilance performance decrements during a week of sleep restricted to 4-5 hours per night. Sleep 1997; 20: 267-277.

15 Tombaugh TN. Trail Making Test A and B: normative data stratified by age and education. Arch Clin Neuropsychol 2004; 19: 203-214

16 Kitabatake A, Inoue M, Asao M, et al. Noninvasive evaluation of pulmonary hypertension by a pulsed Doppler technique. Circulation 1983; 68: 302-309.

17 Kojonazarov BK, Imanov BZ, Amatov TA, et al. Noninvasive and invasive evaluation of pulmonary arterial pressure in highlanders. Eur Respir J 2007; 29: 352-356.

18 Bloch KE, Buenzli JC, Latshang TD, et al. Sleep at high altitude: guesses and facts. J Appl Physiol 2015; 119: $1466-1480$.

19 Leon-Velarde F, Villafuerte FC, Richalet JP. Chronic mountain sickness and the heart. Prog Cardiovasc Dis 2010; 52: $540-549$.

20 Rexhaj E, Rimoldi SF, Pratali L, et al. Sleep-disordered breathing and vascular function in patients with chronic mountain sickness and healthy high-altitude dwellers. Chest 2016; 149: 991-998.

21 Sun S, Oliver-Pickett C, Ping Y, et al. Breathing and brain blood flow during sleep in patients with chronic mountain sickness. J Appl Physiol 1996; 81: 611-618.

22 Thurnheer R, Ulrich S, Bloch KE. Precapillary pulmonary hypertension and sleep-disordered breathing: is there a link? Respiration 2016; in press [https://doi.org/10.1159/000452957].

23 Pratali L, Rimoldi SF, Rexhaj E, et al. Exercise induces rapid interstitial lung water accumulation in patients with chronic mountain sickness. Chest 2012; 141: 953-958.

24 Trip P, Nossent EJ, de Man FS, et al. Severely reduced diffusion capacity in idiopathic pulmonary arterial hypertension: patient characteristics and treatment responses. Eur Respir J 2013; 42: 1575-1585.

25 Kohler M, Stradling JR. Mechanisms of vascular damage in obstructive sleep apnea. Nat Rev Cardiol 2010; 7: $677-685$.

26 Kasai T, Motwani SS, Yumino D, et al. Contrasting effects of lower body positive pressure on upper airways resistance and partial pressure of carbon dioxide in men with heart failure and obstructive or central sleep apnea. J Am Coll Cardiol 2013; 61: 1157-1166.

27 Richalet JP, Rivera-Ch M, Maignan M, et al. Acetazolamide for Monge's disease: efficiency and tolerance of 6-month treatment. Am J Respir Crit Care Med 2008; 177: 1370-1376.

28 Ulrich S, Fischler M, Speich R, et al. Sleep-related breathing disorders in patients with pulmonary hypertension. Chest 2008; 133: 1375-1380.

29 Brack T, Randerath W, Bloch KE. Cheyne-Stokes respiration in patients with heart failure: prevalence, causes, consequences and treatments. Respiration 2012; 83: 165-176. 
30 Ramos AR, Tarraf W, Rundek T, et al. Obstructive sleep apnea and neurocognitive function in a Hispanic/Latino population. Neurology 2015; 84: 391-398.

31 Rosenzweig I, Glasser M, Polsek D, et al. Sleep apnoea and the brain: a complex relationship. Lancet Respir Med 2015; 3: 404-414.

32 Kojonazarov B, Myrzaakhmatova A, Sooronbaev T, et al. Effects of fasudil in patients with high-altitude pulmonary hypertension. Eur Respir J 2012; 39: 496-498.

33 Soria R, Egger M, Scherrer U, et al. Pulmonary artery pressure and arterial oxygen saturation in people living at high or low altitude: systematic review and meta-analysis. J Appl Physiol 2016; in press [https://doi.org/10.1152/ japplphysiol.00394.2016].

34 Aryal N, Weatherall M, Bhatta YK, et al. Blood pressure and hypertension in adults permanently living at high altitude: a systematic review and meta-analysis. High Alt Med Biol 2016; 17: 185-193.

35 Rimoldi SF, Rexhaj E, Pratali L, et al. Systemic vascular dysfunction in patients with chronic mountain sickness. Chest 2012; 141: 139-146. 